\title{
Characterization of Physical, Chemical and Mechanical Properties of Sri Lankan Coir Fibers
}

\author{
Prasad Dhammika Dharmaratne ${ }^{1 *}$, Harsha Galabada' ${ }^{1}$, Randika Jayasinghe ${ }^{2}$, \\ Renuka Nilmini ${ }^{3}$, Rangika Umesh Halwatura ${ }^{1}$ \\ 1 Department of Civil Engineering, University of Moratuwa, Sri Lanka \\ 2 Department of Engineering Technology, Faculty of Technology, Sri Jayawardenapura, Sri Lanka \\ 3 Department of Biosystems Technology, Faculty of Technology, Sri Jayawardenapura, Sri Lanka \\ * Corresponding author's email: makway.cons@gmail.com
}

\begin{abstract}
This study was carried out to determine the characterization of brown coir fiber which is used as a potential reinforcement in polymer composites. The fiber is extracted from the husk of the coconut seeds which are collected in Sri Lanka. Anyhow the above-mentioned characterization can hardly be seen when it comes to the Sri Lankan context. Since the evaluation of their physical, mechanical, and chemical properties are significant before commencing the material development process and applications for this fiber. Several testing were carried out to evaluate the above-mentioned properties. There, the functional groups of coir fiber were obtained by Fourier Transform Infrared analysis and Crystallinity Index and Crystallite size were determined by X-ray diffraction analysis. The surface morphology and cross-sectional features were investigated through Scanning Electron Microscopy. The thermo-gravimetric method was adopted to study the thermal stability of coir fiber. The density and diameter of coir fiber were measured utilizing pychometric method and optical microscope respectively. Tensile strength was measured using an electronic tensometer and then find out the tensile strength, modulus of elasticity, and elongation at breaking point. The average density of brown coir fibers was $1.018 \mathrm{~g} / \mathrm{cm}^{3}$ and average diameters were $0.30 \mathrm{~mm}$. The Crystallinity Index and the crystal-line size were $37.28 \%$ and $0.4331 \mathrm{~nm}$ respectively. Ultimate tensile strength, Young's modulus, and Elongation of the coir fiber were ranging from 94-159 MPa, 1.2-1.8 GPa, and 21-67\%, respectively.
\end{abstract}

Keywords: Coir fibers, Characterization, Physical properties, Chemical properties, Mechanical properties.

\section{INTRODUCTION}

The population of the world is increasing rapidly and the requirements of humans also get increase concerning the population density (Tong $\&$ Qiu, 2020). However, relative to the growth of population density and urbanization, the land area does not get increase. Hence, it is difficult to carry out horizontal construction. Because of that, people have to go for vertical construction like multistoried buildings or apartments to facilitate their requirements. In this scenario, professionals tend to use various techniques to develop lightweight construction materials.
Dead load accumulated by walling material such as bricks and blocks are directly course for the overall apartment weight. This results to increase the capital cost of the construction project as well. However, the dead weight which is coming from solid walls would be drastically reduced by the use of lightweight composite materials for the walls in the high-rise buildings. In this aspect, the usage of lightweight composite wall panels has been identified to be one of the best solutions to rectify this fact (Das, 2012). To prepare such composites, any number of materials are used to prepare such composites and coir fiber is one of those materials. 
When reviewing past literature (Syed et al., 2020; Hussain, 2011; Putra et al., 2020; Hwang et al., 2016) it revealed that the coir fiber is having significant properties and coir fibers can be used as a reinforcing material in polymer-based lightweight composites. Many researches have been performed with polymer matrix composites using coconut fibers.

Coir fiber is one of the versatile and sustainable construction materials in the construction field. It is easily decomposable and consists of lignocellulosic fiber with renewable properties. The price is very low and a vast amount of products can be fabricated using coir fiber. Further, it is having very vital properties such as low thermal conductivity and bulk density etc. (Rejeesh \& Saju, 2017)

Many researches have characterized the coir fiber to evaluate the physical, mechanical and chemical properties. In Brazil, the ultimate tensile strength, young's modulus, and elongation of the lignocellulose coir fibers were investigated as 118-143 MPa, 1.3-2.7 GPa, and 25-60\% respectively (Mathura \& Cree, 2016). Another research was performed and obtained the ultimate tensile strength, young's modulus, and elongation of the lignocellulose as $175 \mathrm{MPa}, 4-6.02 \mathrm{GPa}$, and $30 \%$ respectively (Ho et al., 2012). The diameter range of coir fiber was measured to be $0.272 \mathrm{~mm}$ to $0.513 \mathrm{~mm}$ and the crystallinity index for lignocellulosic coir fiber calculated using Segal empirical method was recorded to be $47.82 \%$ (LomelíRamírez et al., 2018).

According to the official website of International Year for Natural Fibres'2009, Annually 500,000 tons of coconut fiber are manufactured by Sri Lanka and India. Sri Lanka and India are the main exporters and belong to around $90 \%$ world production of coir fibers (Rohit \& Dixit, 2016). If building material could be manufactured from coir fibers, it is a good alternative material to replace existing environmentally hazardous materials (Marimuthu et al., 2019). Anyhow, characterization of coir fiber in Sri Lanka is essential before commencing the fabrication of composites. But characteristics of coir fiber is not available in the Sri Lankan context. Hence authors describe a scientific characterization for brown coconut fiber in the Sri Lankan context.

There was much literature available outlining the characterization process on coir fibers including methods of extraction, different treatment methods, and their properties. Few scholars mention that the physical, mechanical and chemical properties of those species mainly based on their genetic varieties, age of the coconuts from which the fibers are extracted, time of extraction, method of extraction, zone in which the coconut trees are cultivated, soil type of growth area, testing method and conditions of experiments (Verma \& Gope, 2015).

In this research, the physical properties such as diameter, average density, water absorption property, and surface morphology of coir fiber were analyzed. The chemical characterization was performed using Fourier Transform Infrared Analysis (FTIR) and X-Ray Diffraction analysis (XRD). The mechanical properties were evaluated using a tensile test and thermogravimetric analysis.

\section{MATERIALS AND METHODS}

There are three types of coconut fibers are available in Sri Lanka as brown bristle coir, mix coir and mattress coir fiber. The brown coir fiber was selected for this analysis. The fibers required for the study were collected from Western Province in Sri Lanka which is shown in Figure 1.

Processed coconut fibers were purchased from the manufactures however, a further cleaning process was carried out to remove dust and residual particles remaining on fibers. The fibers were washed in running tap water for about 30 minutes to remove coconut pith and it was soaked again for 30 minutes in the distilled water. This process was repeated up to three times. The fibers were undergone to natural drying process under room temperature for $24 \mathrm{hr}$ and finally, it was placed into the oven under $30^{\circ} \mathrm{C}$ temperature for 10 to 12 minutes to remove the remaining moisture on the fiber surface (Syed et al., 2020). These cleaned coir fibers were used for the characterization process.

\section{Diameter measurement}

An optical microscope (CX 410, Olympus, Tokyo, Japan) was used to measure the diameter of the coconut fibers. The three equidistant points were marked on one fiber and diameters were measured on these three points. Then average diameter was calculated and this could be considered as the mean diameter of each single fiber (Widnyana et al., 2020). 5 numbers of coir fibers were undergone to this measurement for more generalized results. 


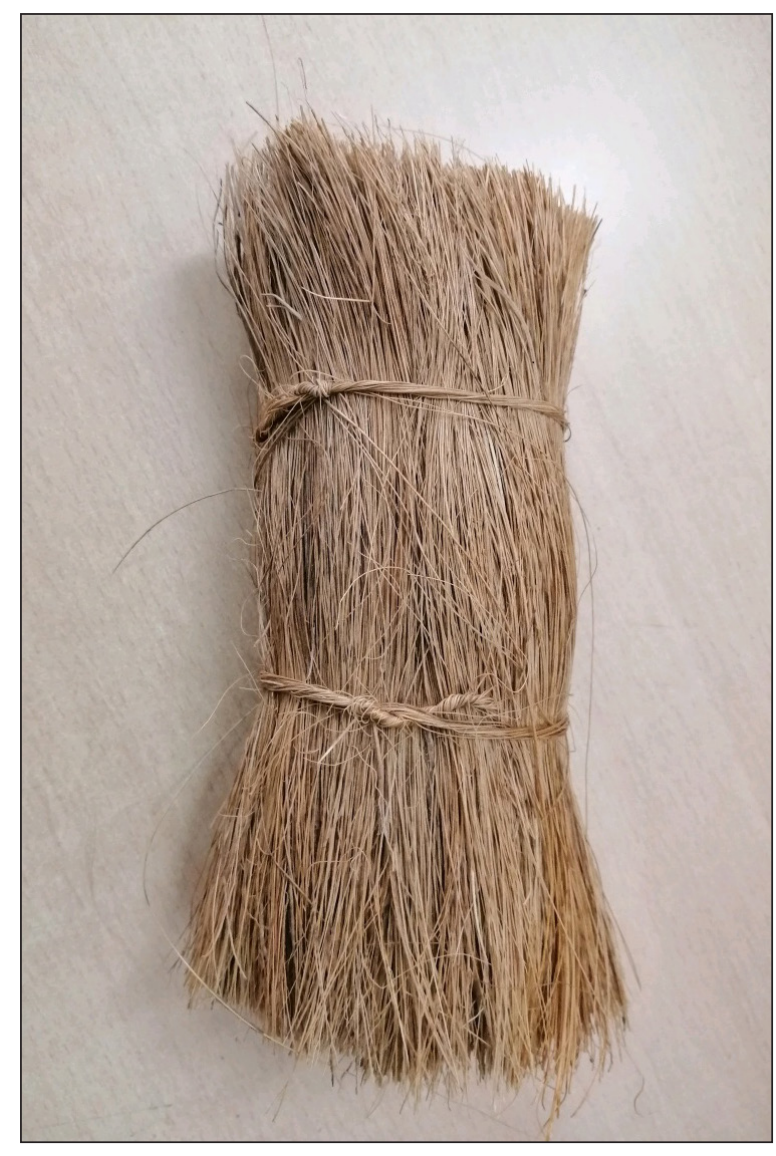

Figure 1. Appearance of coir fiber

\section{DENSITY MEASUREMENT}

The density of fiber was measured using the pycnometric method (Rao \& Rao, 2007). The selected fibres were dried for 96 hours in a desiccator containing silica and they were cut into $5 \mathrm{~mm}$ to $15 \mathrm{~mm}$ length segments. These fiber pieces were put into a pycnometer and then placed in the desiccator again for $24 \mathrm{hr}$. Before commencing the density measurements, the fibres were soaked in toluene solution for 2 hours to remove the microbubbles in the fibres. This testing process was repeated 5 times and the average value was calculated to have more accurate results. The density of the coir fiber " $\rho_{f}$ " was calculated using Eq. (1) (Ravindran et al., 2011).

$$
\rho_{f}=\frac{\left(m_{2}-m_{1}\right)}{\left(m_{3}-m_{1}\right)\left(m_{4}-m_{2}\right)} \rho_{t}
$$

where: $m_{1}$ is the mass of the empty pycnometer $(\mathrm{kg})$, $m_{2}$ is the mass of the pycnometer filled with cut fibers $(\mathrm{kg})$,

$m_{3}$ is the mass of the pycnometer filled with toluene $(\mathrm{kg})$, $m_{4}$ is the mass of the pycnometer filled with cut fibres and toluene $(\mathrm{kg})$, and $\rho_{\mathrm{t}}$ is the density of toluene $\left(\mathrm{g} / \mathrm{cm}^{3}\right)$ which is $0.866 \mathrm{~g} / \mathrm{cm}^{3}$.

\section{Scanning Electron Microscopic analysis (SEM)}

The surface morphology and cross-sectional features of fibers were observed using scanning electron microscopy. Before the test, the coir samples were coated with a thin conductive material layer of gold by a plasma sputtering apparatus to prevent the potential accumulation of the electrical charges during analysis (Niresh et al., 2019) (Manimaran et al., 2018). The cross-sections and longitudinal views of the fibers were examined at different magnifications. The plasma sputtering apparatus and scanning electronic microscope are shown in Figure 2(a) and Figure 2(b) respectively.

\section{Fourier Transform Infrared Analysis (FTIR)}

Fourier transform infrared spectra of the coir fiber was determined using a "Perkin Elmer Spectrum" instrument using Attenuated Total Reflectance (ATR) technique to determine the chemical composition of the brown coir (Sgriccia et al., 2008). The Infrared Radiation (IR) spectrum was obtained and the analysis was carried out with a FTIR spectrometer with 32 scans per minute and a resolution of $4 \mathrm{~cm}^{-1}$ over the wavenumber range from 4000 to $500 \mathrm{~cm}^{-1}$ (Niresh et al., 2019). A coir fiber sample was placed on the sample plate and pressed with a sample holder arm. The size and shape of the peaks are helped to determine the functional groups present in fiber (Moshi et al., 2020).

\section{X-ray diffraction analysis (XRD)}

The X-ray diffraction analysis was performed using the "Ragaku, Ultima IV X-ray Diffractometer" system with Ni-filtered $\mathrm{CuK} \alpha$ radiation. The powdered sample was used for X-ray diffraction analysis. The diffracted intensity of $\mathrm{CuK} \alpha$ radiation was recorded within the $2 \theta$ range, varying from $3^{\circ}$ to $70^{\circ}$ at $45 \mathrm{kV}$ and $40 \mathrm{~mA}$. The speed of the goniometer was $20 \mathrm{~min}^{-1}$. The Crystallinity Index (CI) was calculated using Segal empirical method which is given using the following Equation (2).

$$
C I=\frac{I_{200}-I_{a m}}{I_{200}} \times 100 \%
$$


a)

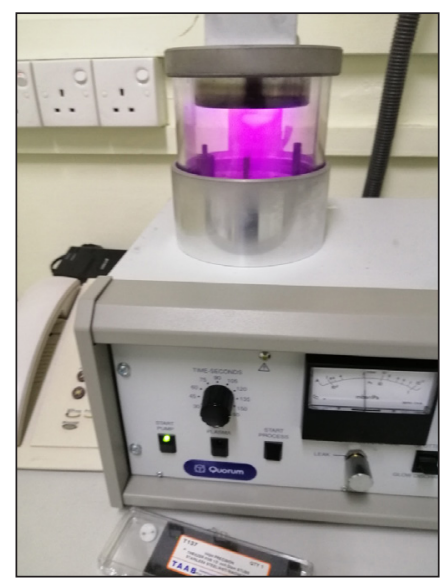

b)

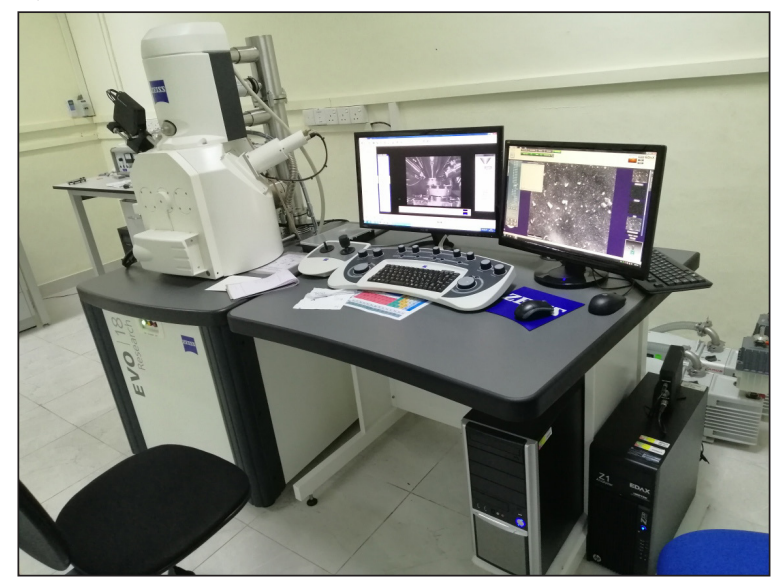

Figure 2. (a) Plasma sputtering apparatus and (b) SEM equipment

where: $I_{200}$ and $I_{a m}$ are the maximum intensity of diffraction of the lattice peak at a $2 \theta$ angle of between $22^{\circ}$ and $23^{\circ}$, which represents both crystalline and amorphous materials. The intensity of diffraction of the amorphous material, which is taken at a $2 \theta$ angle between $18^{\circ}$ and $19^{\circ}$ where the intensity is at a minimum respectively. Crystallite Size (CrS) was calculated using Scherrer's formula Equation (3).

$$
\operatorname{CrS}=\frac{0.89 \lambda}{\beta \operatorname{COS} \theta}
$$

where: 0.89 is Scherrer's constant,

$\beta$ is the peak's full width at half-maximum of the peak and

$\lambda$ is the wavelength of the X-ray $(0.154 \mathrm{~nm})$,

$\theta$ is the Bragg's angle (Liu et al., 2019).

\section{Tensile Test}

The tensile test was carried out using a universal testing machine of "INSTRON tensile tester, Model 4465" according to the ASTM D 3822-07 standard. The test was implemented at the ambient temperature $20^{\circ} \mathrm{C}$ with $65 \%$ relative humidity. The gauge length was varied to determine its effect on the tensile properties. The fiber samples of various gauge lengths of $10 \mathrm{~mm}, 20 \mathrm{~mm}, 30 \mathrm{~mm}$, $40 \mathrm{~mm}$, and $50 \mathrm{~mm}$ were undergone for the test [Moshi et al. 2020] and crosshead speed was maintained from $6,12,18,24$, and $30 \mathrm{~mm} / \mathrm{min}$ respectively. During the test, the fibers were fixed with pneumatic grips under a pressure of $0.4 \mathrm{MPa}$.
Due to the variabilities of the natural fibers, more than 30 numbers of samples for each gauge length were tested and the average value of the ultimate tensile strength (UTS), young's modulus (YM), and elongation were obtained (Lomelí-Ramírez et al., 2018; Ravindran et al., 2011)

\section{Thermogravimetric Analysis (TGA)}

The thermal stability of coir fibers was investigated using a thermo-gravimetric analyzer (TGA-SDT-650). The $5 \mathrm{mg}$ of fiber sample was weighed and placed in an aluminum pan and then heated from $20^{\circ} \mathrm{C}$ to $850{ }^{\circ} \mathrm{C}$ at a heating rate of $10{ }^{\circ} \mathrm{C} / \mathrm{min}$ at a flow rate of $100 \mathrm{ml} / \mathrm{min}$ under an argon atmosphere. The weight changes of coir fiber in the percentages as a function of increasing temperature with a constant heating rate were recorded (Chin et al., 2020)

\section{RESULTS AND DISCUSSIONS}

Since the diameter and sectional properties vary along the length of the coir, it is difficult to measure the diameter more accurately. Table 1 depicts the values taken for 3 consecutive distances for the 5 coir samples. The average diameter was calculated as $0.30 \mathrm{~mm}$. The diameter measurement of coir fiber using the optical microscope is shown in Figure 3.

\section{Density measurement}

The average density value of the coir fiber was obtained $1.018 \mathrm{~g} / \mathrm{cm}^{3}$. Table 2 shows some of the densities of natural fibers and synthetic fibers. 
Table 1. Diameter Readings

\begin{tabular}{|c|c|c|c|c|}
\hline \multicolumn{5}{|c|}{ Diameter / mm } \\
\hline Sample No. & Point-1 & Point-2 & Point-3 & Average \\
\hline 1 & 0.26 & 0.31 & 0.33 & 0.30 \\
\hline 2 & 0.36 & 0.33 & 0.30 & 0.33 \\
\hline 3 & 0.31 & 0.28 & 0.28 & 0.29 \\
\hline 4 & 0.34 & 0.31 & 0.30 & 0.32 \\
\hline 5 & 0.28 & 0.28 & 0.29 & 0.28 \\
\hline & & & & $\mathbf{0 . 3 0}$ \\
\hline
\end{tabular}

However, the densities of some natural fibers are expressed at a higher value than the proposed coir fiber (Indran \& Raj, 2015).

These natural fibers could be used to satisfy the reinforcement requirement for developing the composites. Then would be added the value of being lightweight, reviewable and bio degradable [Lomelí-Ramírez et al., 2018]. It is significant to compare density values with other natural fibers for investigation purposes. The broadly used synthetic fibers like E-glass fiber and carbon fiber are shown the densities of $2.56 \mathrm{~g} / \mathrm{cm}^{3}$ and $1.4-1.8 \mathrm{~g} / \mathrm{cm}^{3}$ respectively (Roy et al., 2001). The environmental condition and rate of growth of the plant would cause variation of density values (Moshi et al., 2020). Further the process of fiber extraction, available moisture content of the fiber, condition of the existing soil that plant has grown have resulted in the variation of densities (Rao \& Rao, 2007).

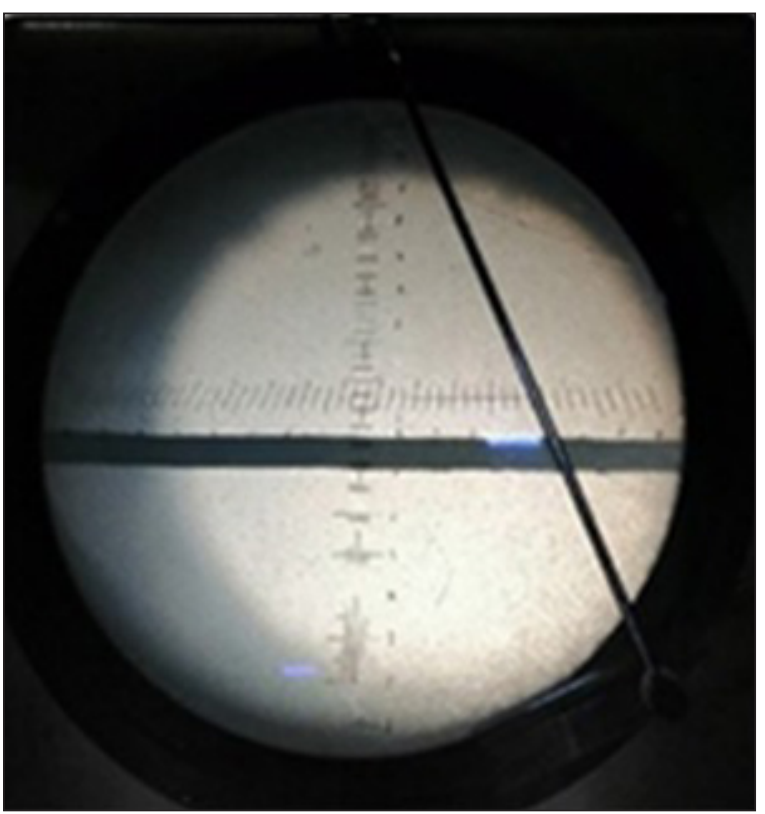

Figure 3. Image of coir fiber through optical microscope

\section{Scanning Electronic Microscopy analysis (SEM)}

The natural fibers are utilized as reinforcement material when producing composites. The fiber surface inconsistencies may cause during the extracting process, because of the fibers age, ecological effects and variation of soil. Therefore, the manufacturer should be keen on sample preparation (Binoj et al., 2016). The SEM offers magnified high-resolution images of the fibers focusing the electron beam on the cross-section and longitudinal surface of the fiber (Sanjay et al., 2019). Figure 4 shows the sectional micrographs of scanning electron microscopic of brown coir fiber in different magnifications. The microfibrils are in different sizes and consists of thick walls (Lomelí-Ramírez et al., 2018). Figure 5 exhibits the SEM images of surface features and morphology of brown coir fiber. The fiber observes a rough surface with many holes and channels. It causes to wettability of the fiber and enhances bonding when it is utilized as reinforcement in manufacturing the composites. The surface roughness of coir fiber may help to bond fiber with matrix material and it influences to generate mechanical interlocking between fiber and matrix material (Binoj et al., 2016). Further, the understanding of the behavior of acoustic and thermal properties, studying surface morphology of coir is very significant (Niresh et al., 2019).

This characterization study reveals that whether the suitability of reinforcement material for a particular composite application or not. Coir consists of a large amount of hemicellulose and cellulose which are bond together. The chemical treatment causes to reduction of hemicellulose and cellulose. Because of this, the proper bonding between fiber and matrix material could be seen

Table 2. Fiber Density (Indran \& Raj, 2015)

\begin{tabular}{|l|c|}
\hline \multicolumn{1}{|c|}{ Fiber } & Density $\left(\mathrm{g} / \mathrm{cm}^{3}\right)$ \\
\hline Natural fiber & \\
\hline Jute & 1.30 \\
\hline Flax & 1.50 \\
\hline Hemp & 1.47 \\
\hline Kenaf & 1.30 \\
\hline Sisal & 1.50 \\
\hline Banana & 1.35 \\
\hline Synthetic Fiber & \\
\hline E-glass & 2.56 \\
\hline Carbon fiber & $1.4-1.8$ \\
\hline
\end{tabular}


a)

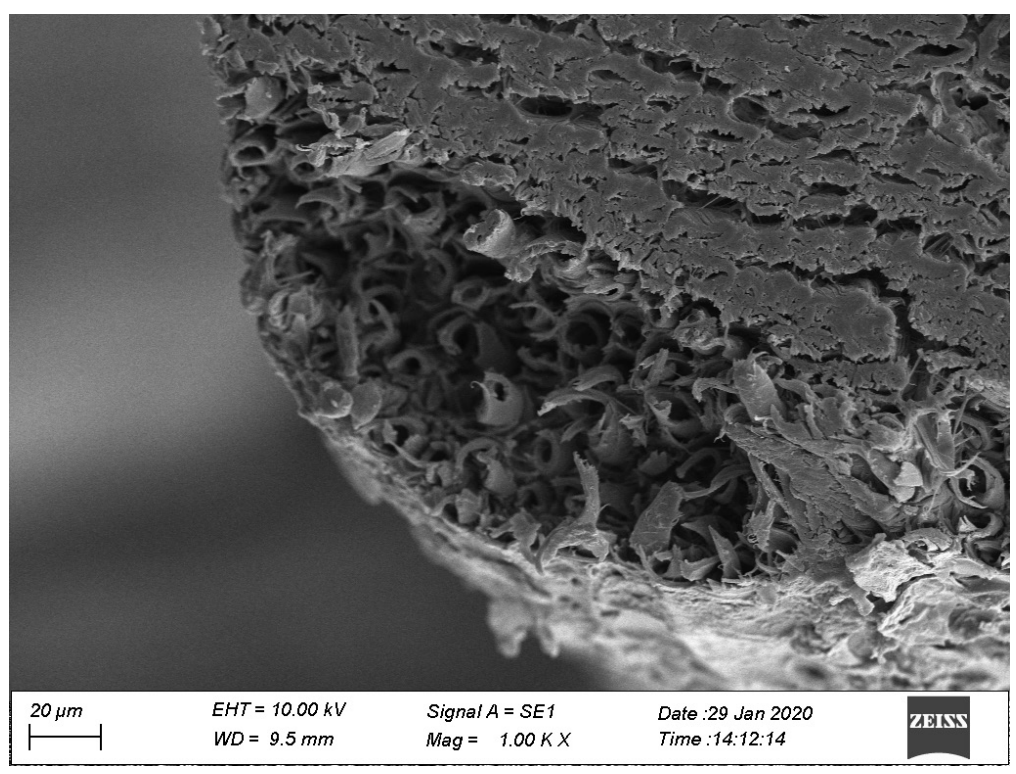

b)

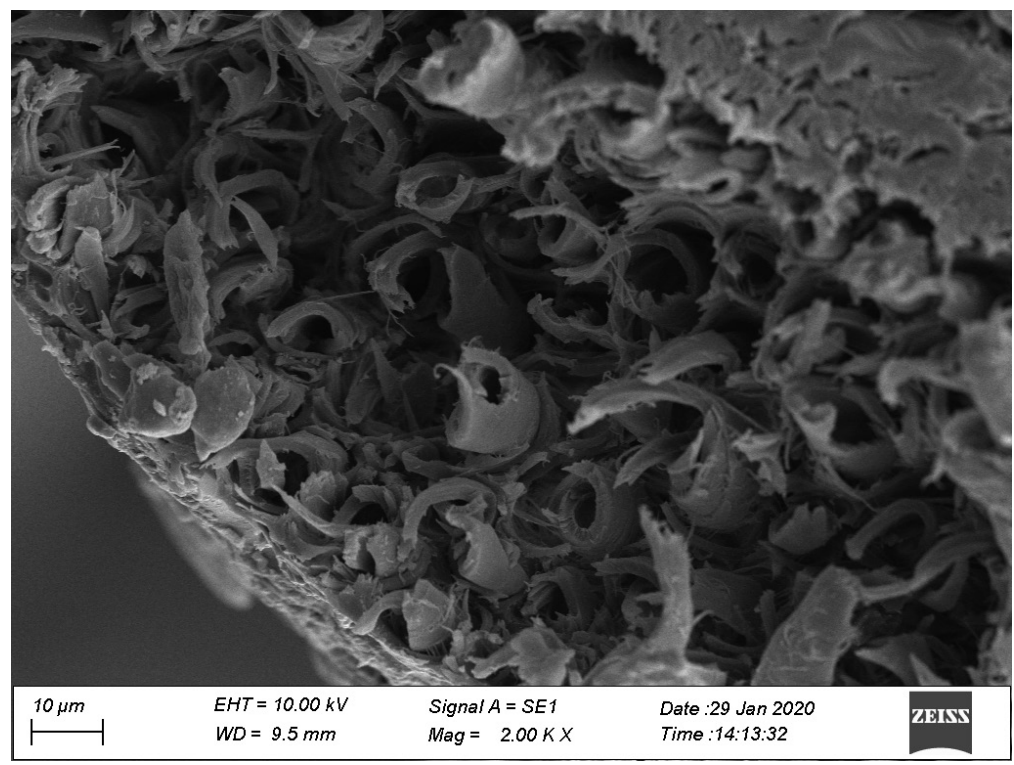

Figure 4. SEM images of transverse cross-sections of coir fibers (a) enlarged view showing the cellular wall of a fiber at magnification 1000 times (b) magnification 2000 times

during the development of composites (Sgriccia et al., 2008).

Figure 5a to Figure 5d show the longitudinal micrographs of brown coir fiber. Porous parts are observed on the surface of the fiber (Figure 5a, $5 b, 5 c)$. Hemicellulose content could be seen in the white layer in the SEM images of the fiber in Figure $5 \mathrm{~d}$. If the fiber surface is smooth, it would not cause proper adhesion between fiber and matrix. Then the surface modification is required for the fiber to achieve good mechanical properties when manufacturing of composite (Moshi et al., 2020). Studying the mechanical properties of the composites, fiber surface characterization like surface roughness, pore size, interfacial bonding between the fiber and matrix, and chemical composition in material are important (da Silva Moura et al., 2019).

\section{FTIR analysis}

This is one of the techniques used for the chemical characterization of the natural fibers. It helps to identify the molecules and functional groups available in natural fibers. Figure 6 shows the FTIR spectrum of brown coir fiber. The Fourier Transform Infrared spectra were observed between 500 to $4000 \mathrm{~cm}^{-1}$ range. The maximum absorption peak of $3338 \mathrm{~cm}^{-1}$ was recorded due to the availability of the hydroxyl (-OH) group 
a)

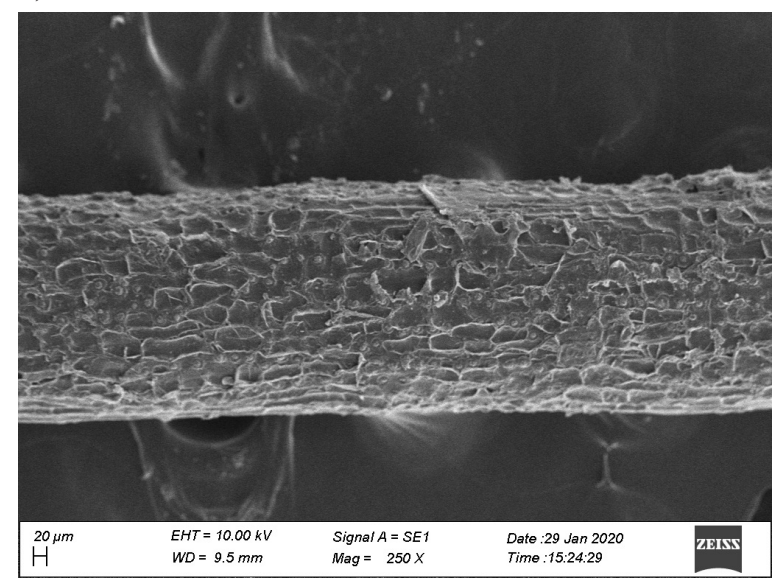

c)

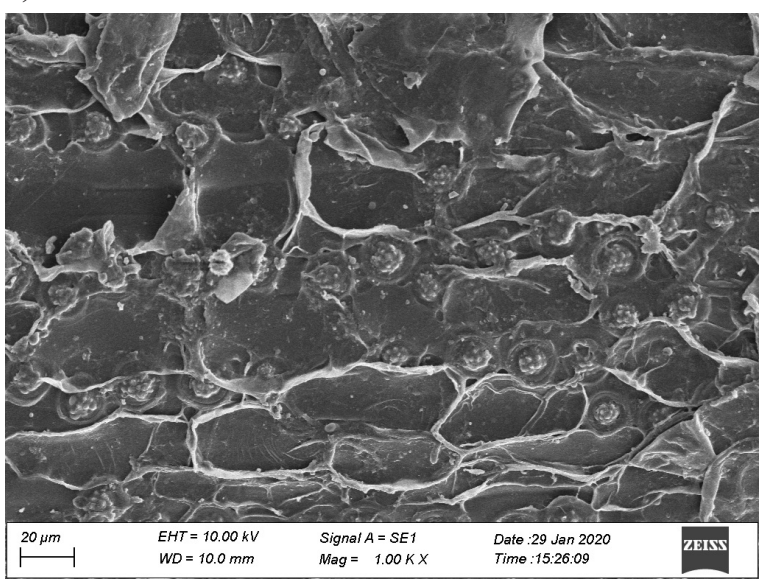

b)

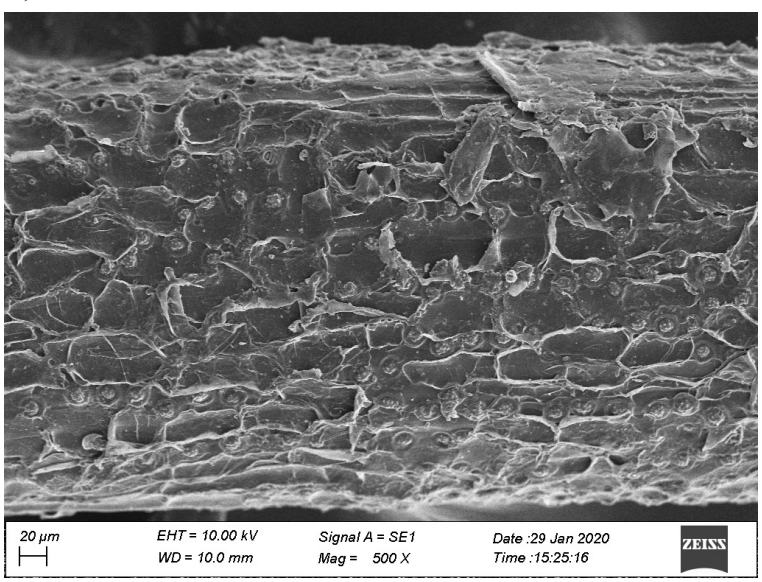

d)

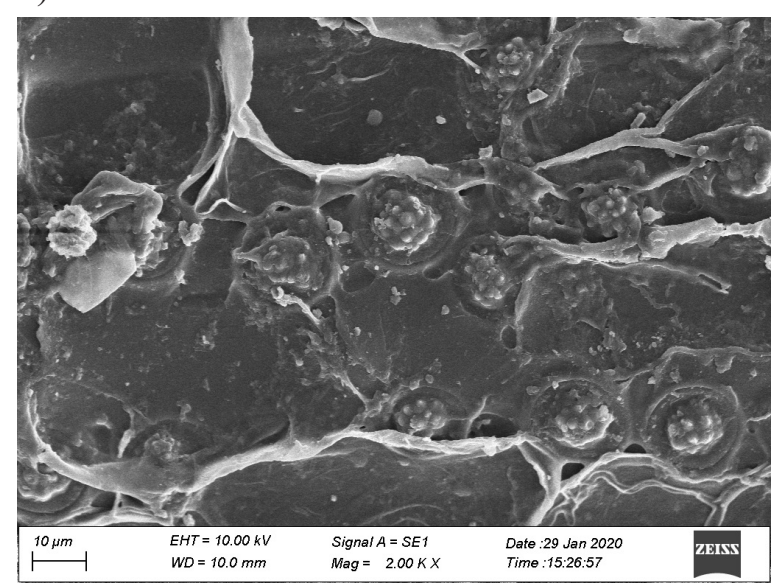

Figure 5. Longitudinal SEM micrographs of Brown coir in (a) magnification 250

(b) magnification 500 (c) magnification 1000 (d) magnification 2000

in the cellulose group in fiber material (Baskaran et al., 2018) (Theivasanthi et al., 2018). The peaks occurred at $2845 \mathrm{~cm}^{-1}$ highlight the presence of dispersed wax material in the coir fiber $(\mathrm{C} \equiv \mathrm{C}$ stretching). The peak appeared at $1600 \mathrm{~cm}^{-1}$ due to the stretching of the $\mathrm{C}=\mathrm{O}$ group indicated the hemicellulose content in coir fiber (Indran \& Raj, 2015). The region between 1252 to $1439 \mathrm{~cm}^{-1}$ is correlated with the lignin content category of the $\mathrm{C}=\mathrm{H}$ group (Hyness et al., 2018). Then after studying the chemical structure of cellulose, hemicellulose and lignin, it could be decided to the availability of above in the selected brown coir fiber.

\section{X-ray diffraction analysis}

$\mathrm{X}$-ray diffraction analysis was used to evaluate the crystallinity index of the natural fibers which is shown in Figure 7. It can be noticed that the main crystalline peak occurred at $22.48^{\circ}$, which corresponds to the crystallographic plane of cellulose-I. The lower-intensity peak at $17.48^{\circ}$ indicates the fiber contains higher amounts of amorphous material such as hemicelluloses, amorphous cellulose, lignin, and pectin (Mayandi et al., 2016). According to Figure $7, I_{200}$ and $I_{a m}$ heights of the peaks at $904.2 \mathrm{cps}$ and $658.63 \mathrm{cps}$ respectively. The calculated crystallinity index using (2) was $37.28 \%$, for the coir, which is less than other natural fibers reported are wrighitia tinctoria seed fiber $(49.2 \%)$, ramie fiber (58\%), Sansevieria cylindrica leaf fibers (60\%), Raffia textiles (64\%), sisal (71\%), jute (71\%), flax (80\%), hemp (88\%), Date palm (38.5\%) (Al-Khanbashi et al., 2005) (Ravindran et al., 2011) However, the crystallite size of the coir was determined as $0.4331 \mathrm{~nm}$ using Scherrer's formula (See (1)). The crystallite size for some of the natural fibers are R. textilis $(32 \mathrm{~nm})$, ramie fibers $(16 \mathrm{~nm})$, cotton fibers $(5.5 \mathrm{~nm})$, cornstalk fibers $(3.8 \mathrm{~nm})$ and flax fibers (2.8 nm) (Ravindran et al., 2011) 


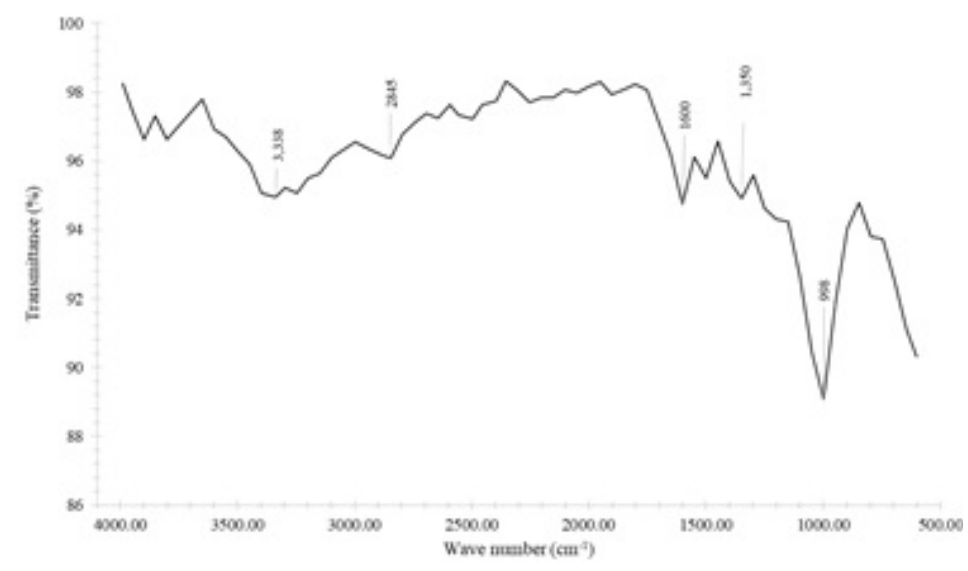

Figure 6. FTIR spectra of the coir fiber sample

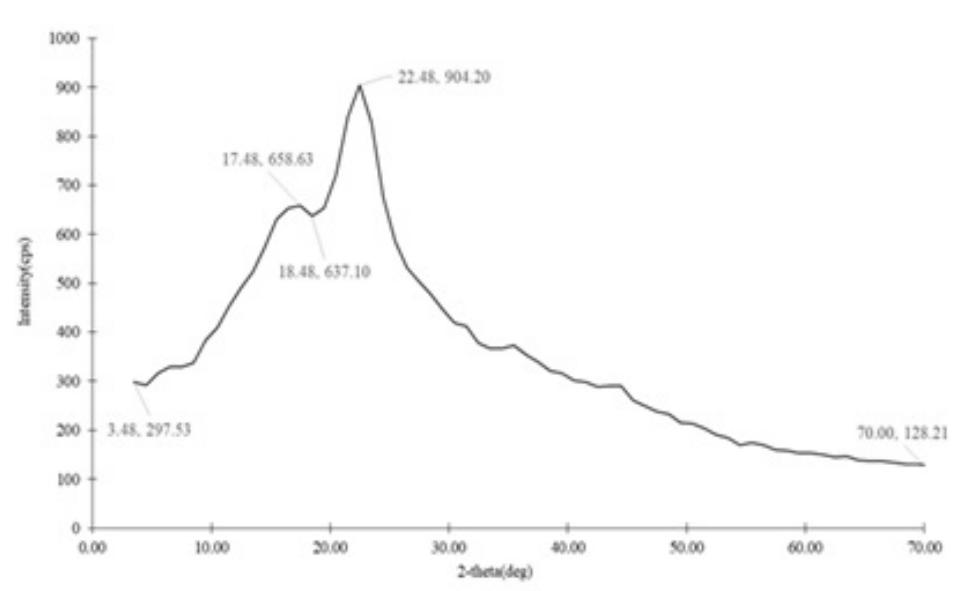

Figure 7. XRD spectrum of brown coir fiber

\section{Tensile test}

It is very significant to study the mechanical properties of coir fiber and interfacial bonding characteristics, before manufacture the composites (da Silva Moura et al., 2019). The tensile properties of natural fibers are mainly dependent on test conditions, fiber extracted species, and properties of fiber dimensions (Bezazi et al., 2014). More than 30 coir fiber samples were tested varying gauge lengths from $1 \mathrm{~cm}$ to $5 \mathrm{~cm}$ each. It can be noted that when considered gauge length increases, the cross-section also varies with the length. Then it is affected by the variation of the tensile strength (Binoj et al., 2016). However in the present study, Ultimate tensile strength, Young's modulus and Elongation of the coir fiber were ranging from $94-159 \mathrm{MPa}, 1.2-1.8 \mathrm{GPa}$, and $21-67 \%$, respectively. Table 3 shows the published values of the above mechanical properties of natural fibers after performing the tensile test.

\section{TGA analysis results}

The Thermogravimetric analysis is carried out to study the thermal stability of natural fibers and their composites. The physical and chemical properties can be determined as a function of increasing temperature while maintaining a steady heating rate (Sanjay et al., 2019). The thermal degradation of natural fiber occurs consequently from hemicellulose, cellulose, lignin, wax and other components with increment of temperature (Moshi et al., 2020). Further TGA is used to assess information regarding certain physical properties, such as absorption, adsorption, desorption, second-order phase transitions, vaporization and sublimation. It is also possible to determine chemical properties such as de-solvation, chemisorptions, solid-gas reactions and decomposition. Figure 8 depicts TGA and DTG curves of powdered brown coir fiber sample. It is observed that the small weight loss occurs up to $125^{\circ} \mathrm{C}$ due to 
Table 3. Tensile properties of coir fiber and other natural fibers (Sarikanat et al., 2014; Scalici et al., 2016; Seki et al., 2013)

\begin{tabular}{|c|c|c|c|c|c|}
\hline Fiber & $\begin{array}{c}\text { Tensile Strength } \\
(\mathrm{MPa})\end{array}$ & $\begin{array}{c}\text { Young's Modulus } \\
\text { (GPa) }\end{array}$ & Fiber & $\begin{array}{c}\text { Tensile Strength } \\
(\mathrm{MPa})\end{array}$ & $\begin{array}{c}\text { Young's Modulus } \\
(\mathrm{GPa})\end{array}$ \\
\hline Coir & $95-174$ & $5.5-12.6$ & Flax & $500-1500$ & 27.6 \\
\hline Okra & 281 & 16.5 & Cotton & $200-400$ & $5.5-12.6$ \\
\hline Ferula & 475 & 52.7 & Ramie & $400-938$ & $61.4-128$ \\
\hline Althaea & 415 & 65.4 & Hemp & 690 & 70 \\
\hline Piassava & 77 & 2.93 & Pineapple & $362-748$ & $20-80$ \\
\hline Alfa & 250 & 20 & Kenaf & 930 & 53 \\
\hline Sansevieria & $50-585$ & $2.5-7.8$ & Sisal & $511-635$ & $9.4-22$ \\
\hline Arundo culm & 248 & 9.4 & Abaca & 756 & 31.1 \\
\hline Arundo leaf & 193.5 & 18 & Henequen & 500 & 13.2 \\
\hline Luffa cylindrica & 385 & 12.2 & Banana & $700-800$ & $27-32$ \\
\hline Jute & $400-773$ & $10-30$ & & & \\
\hline
\end{tabular}

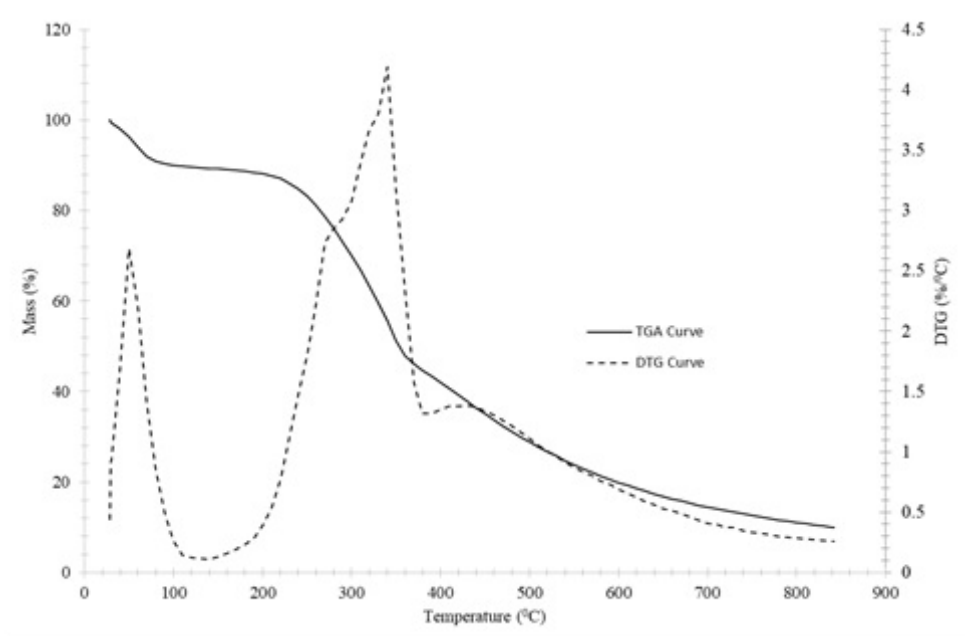

Figure 8. TGA Graph of brown coir fiber

moisture and volatile organic compound evaporation from the sample. There is no considerable weight loss until $220{ }^{\circ} \mathrm{C}$ and it indicates good thermal stability of the fiber with the increment of temperature (Binoj et al., 2016). The second degradation peak occurred at $280-340{ }^{\circ} \mathrm{C}$, which is associated with degradation of hemicellulose and pectin, observed only for coir fiber. The third 340-380 ${ }^{\circ} \mathrm{C}$ peak corresponds to cellulose thermal degradation. A narrow peak extending from 220 to $680{ }^{\circ} \mathrm{C}$ highlighted the presence of Lignin (dos Santos et al., 2019).

\section{CONCLUSION}

The coir fibers were characterized by observing the physical, chemical and mechanical properties. The observed average diameter and density of coir fiber were $0.31 \mathrm{~mm}$ and $1.018 \mathrm{~g} / \mathrm{cm}^{3}$.
The SEM analysis resulted in the surface characterization of features of roughness, pore size, interfacial bonding between the fiber and matrix and available impurities. The FTIR noticed the chemical characterization of the coir fibers and it was cleared to identify the molecules and functional groups available in Sri Lankan coir fibers and which confirms the availability of cellulose, hemicellulose, lignin and wax content etc. The $\mathrm{X}$-ray diffraction analysis was used to calculate the crystallinity index and the crystallite size of coir fiber and which were calculated as $37.28 \%$ and $0.4331 \mathrm{~nm}$ respectively and which were less than other natural fibers reported. In the tensile test, ultimate tensile strength, young's modulus and elongation of the coir fiber were ranging from 94-159 $\mathrm{MPa}, 1.2-1.8 \mathrm{GPa}$, and 21-67\% respectively. Thermogravimetric analysis exhibited that Sri Lankan coir fibers are thermally stable below $220^{\circ} \mathrm{C}$. 


\section{Acknowledgements}

The authors would like to acknowledge Mrs. W.B.U. Rukma, Technical Officer of Construction Management division of University of Moratuwa. And also the staff of the Department of Textile and Clothing Technology laboratory and the Department of Material Science and Engineering testing laboratory of the University of Moratuwa for the support given to successful this study.

This research did not receive any specific grant from any funding agencies in the public, commercial, or not-for-profit sectors.

\section{REFERENCES}

1. Al-Khanbashi, A., Al-Kaabi, K., \& Hammami, A. (2005). Date palm fibers as polymeric matrix reinforcement: Fiber characterization. Polymer Composites, 26(4), 486-497. https://doi.org/10.1002/ pc. 20118

2. Baskaran, P.G., Kathiresan, M., Senthamaraikannan, P., \& Saravanakumar, S.S. (2018). Characterization of New Natural Cellulosic Fiber from the Bark of Dichrostachys Cinerea. Journal of Natural Fibers, 15(1), 62-68. https://doi.org/10.1080/1544 0478.2017 .1304314

3. Bezazi, A., Belaadi, A., Bourchak, M., Scarpa, F., \& Boba, K. (2014). Novel extraction techniques, chemical and mechanical characterisation of Agave americana L. natural fibres. Composites Part B: Engineering, 66, 194-203. https://doi.org/10.1016/j. compositesb.2014.05.014

4. Binoj, J.S., Edwin Raj, R., Sreenivasan, V.S., \& Rexin Thusnavis, G. (2016). Morphological, physical, mechanical, chemical and thermal characterization of sustainable Indian Areca fruit husk fibers (Areca Catechu L.) as potential alternate for hazardous synthetic fibers. Journal of Bionic Engineering, 13(1), 156-165. https://doi.org/10.1016/ S1672-6529(14)60170-0

5. Chin, S.C., Tee, K.F., Tong, F.S., Ong, H.R., \& Gimbun, J. (2020). Thermal and mechanical properties of bamboo fiber reinforced composites. Materials Today Communications, 23, 100876. https://doi. org/10.1016/j.mtcomm.2019.100876

6. da Silva Moura, A., Demori, R., Leão, R.M., Crescente Frankenberg, C.L., \& Campomanes Santana, R.M. (2019). The influence of the coconut fiber treated as reinforcement in PHB (polyhydroxybutyrate) composites. Materials Today Communications, 18, 191-198. https://doi.org/10.1016/j. mtcomm.2018.12.006

7. Das, S. (2012). Fabrication and characterization of raw and bleached treatment coir fiber Reinforced polymer composite [MSc]. http://ethesis.nitrkl. ac.in/3526/

8. dos Santos, J.C., de Oliveira, L.Á., Vieira, L.M.G., Mano, V., Freire, R.T., \& Panzera, T.H. (2019). Eco-friendly sodium bicarbonate treatment and its effect on epoxy and polyester coir fibre composites. Construction and Building Materials, 211, 427-436.

9. Ho, M., Wang, H., Lee, J.-H., Ho, C., Lau, K., Leng, J., \& Hui, D. (2012). Critical factors on manufacturing processes of natural fibre composites. Composites Part B: Engineering, 43(8), 3549-3562. https:// doi.org/10.1016/j.compositesb.2011.10.001

10. Hussain, S.A. (2011). Mechanical properties of green coconut fiber reinforced hdpe polymer composite. International Journal of Engineering Science and Technology, 3(11), 12.

11. Hwang, C.-L., Tran, V.-A., Hong, J.-W., \& Hsieh, Y.-C. (2016). Effects of short coconut fiber on the mechanical properties, plastic cracking behavior, and impact resistance of cementitious composites. Construction and Building Materials, 127, 984-992. https://doi.org/10.1016/j.conbuildmat.2016.09.118

12. Hyness, N.R.J., Vignesh, N.J., Senthamaraikannan, P., Saravanakumar, S.S., \& Sanjay, M.R. (2018). Characterization of New Natural Cellulosic Fiber from Heteropogon Contortus Plant. Journal of Natural Fibers, 15(1), 146-153. https://doi.org/10.1080/ 15440478.2017.1321516

13. Indran, S., \& Raj, R.E. (2015). Characterization of new natural cellulosic fiber from Cissus quadrangularis stem. Carbohydrate Polymers, 117, 392-399. https://doi.org/10.1016/j.carbpol.2014.09.072

14. Liu, Y., Lv, X., Bao, J., Xie, J., Tang, X., Che, J., Ma, Y., \& Tong, J. (2019). Characterization of silane treated and untreated natural cellulosic fibre from corn stalk waste as potential reinforcement in polymer composites. Carbohydrate Polymers, 218, 179187. https://doi.org/10.1016/j.carbpol.2019.04.088

15. Lomelí-Ramírez, M.G., Anda, R.R., Satyanarayana, K.G., Muniz, G.I.B. de, \& Iwakiri, S. (2018). Comparative Study of the Characteristics of Green and Brown Coconut Fibers for the Development of Green Composites. BioResources, 13(1), 1637-1660.

16. Manimaran, P., Senthamaraikannan, P., Murugananthan, K., Sanjay, M.R. (2018). Physicochemical properties of new cellulosic fibers from azadirachta indica plant. Journal of Natural Fibers, 15(1), 29-38. https:// doi.org/10.1080/15440478.2017.1302388

17. Marimuthu, K.P., Kumar, S.M., Kumar, V.R., \& Govindaraju, H.K. (2019). Characterization of Mechanical Properties of Epoxy Reinforced with Glass Fiber and Coconut Fiber. Materials Today: Proceedings, 16, 661-667. https://doi.org/10.1016/j. matpr.2019.05.143

18. Mathura, N., \& Cree, D. (2016). Characterization and mechanical property of Trinidad coir fibers. 
Journal of Applied Polymer Science, 133(29). https://doi.org/10.1002/app.43692

19. Mayandi, K., Rajini, N., Pitchipoo, P., Jappes, J.T. W., \& Rajulu, A. V. (2016). Extraction and characterization of new natural lignocellulosic fiber $\mathrm{Cy}$ perus pangorei. International Journal of Polymer Analysis and Characterization, 21(2), 175-183. https://doi.org/10.1080/1023666X.2016.1132064

20. Moshi, A.A.M., Ravindran, D., Bharathi, S.R.S., Indran, S., Saravanakumar, S.S., \& Liu, Y. (2020). Characterization of a new cellulosic natural fiber extracted from the root of Ficus religiosa tree. International Journal of Biological Macromolecules, 142, 212-221. https://doi.org/10.1016/j. ijbiomac.2019.09.094

21. Sanjay M.R., Siengchin, S., Parameswaranpillai, J., Jawaid, M., Pruncu, C.I., \& Khan, A. (2019). A comprehensive review of techniques for natural fibers as reinforcement in composites: Preparation, processing and characterization. Carbohydrate Polymers, 207, 108-121. https://doi.org/10.1016/j. carbpol.2018.11.083

22. Niresh J., Archana N., Karthink T., Tan Wei Hong (2019). Physical, Chemical, Morphological and Thermal Characterization of Natural Fibers. Tekstil ve Konfeksiy. https://doi.org/10.32710/ tekstilvekonfeksiyon.375784

23. Putra, A.E.E., Renreng, I., Arsyad, H., \& Bakri, B. (2020). Investigating the effects of liquid-plasma treatment on tensile strength of coir fibers and interfacial fiber-matrix adhesion of composites. Composites Part B: Engineering, 183, 107722. https:// doi.org/10.1016/j.compositesb.2019.107722

24. Rao, K.M.M., \& Rao, K.M. (2007). Extraction and tensile properties of natural fibers: Vakka, date and bamboo. Composite Structures, 77(3), 288-295. https://doi.org/10.1016/j.compstruct.2005.07.023

25. Ravindran, D., Manikandan, V., \& Narayanasamy, R. (2011). Microstructural, physico-chemical and mechanical characterisation of Sansevieria cylindrica fibres - An exploratory investigation. Materials \& Design, 32(1), 453-461. https://doi.org/10.1016/j. matdes.2010.06.004

26. Rejeesh, C.R., \& Saju, K.K. (2017). Methods and materials for reducing flammability behaviour of coir fibre based Composite Boards: A Review. Materials Today: Proceedings, 4(9), 9399-9407. https:// doi.org/10.1016/j.matpr.2017.06.193

27. Rohit, K., \& Dixit, S. (2016). A Review-Future Aspect of Natural Fiber Reinforced Composite. Polymers from Renewable Resources, 7(2), 43-59. https://doi.org/10.1177/204124791600700202
28. Roy, R., Sarkar, B.K., \& Bose, N.R. (2001). Behaviour ofE-glass fibre reinforced vinylester resin composites under impact fatigue. Bulletin of Materials Science, 24(2), 137-142. https://doi.org/10.1007/BF02710090

29. Sarikanat, M., Seki, Y., Sever, K., \& Durmuşkahya, C. (2014). Determination of properties of Althaea officinalis L. (Marshmallow) fibres as a potential plant fibre in polymeric composite materials. Composites Part B: Engineering, 57, 180-186. https:// doi.org/10.1016/j.compositesb.2013.09.041

30. Scalici, T., Fiore, V., \& Valenza, A. (2016). Effect of plasma treatment on the properties of Arundo Donax L. leaf fibres and its bio-based epoxy composites: A preliminary study. Composites Part B: Engineering, 94, 167-175. https://doi.org/10.1016/j. compositesb.2016.03.053

31. Seki, Y., Sarikanat, M., Sever, K., \& Durmuşkahya, C. (2013). Extraction and properties of Ferula communis (chakshir) fibers as novel reinforcement for composites materials. Composites Part B: Engineering, 44(1), 517-523. https://doi.org/10.1016/j. compositesb.2012.03.013

32. Sgriccia, N., Hawley, M. C., \& Misra, M. (2008). Characterization of natural fiber surfaces and natural fiber composites. Composites Part A: Applied Science and Manufacturing, 39(10), 1632-1637. https://doi.org/10.1016/j.compositesa.2008.07.007

33. Syed, H., Nerella, R., \& Madduru, S. R. C. (2020). Role of coconut coir fiber in concrete. Materials Today: Proceedings, S2214785320305824. https://doi. org/10.1016/j.matpr.2020.01.477

34. Theivasanthi, T., Anne Christma, F.L., Toyin, A. J., Gopinath, S.C.B., \& Ravichandran, R. (2018). Synthesis and characterization of cotton fiberbased nanocellulose. International Journal of Biological Macromolecules, 109, 832-836. https://doi. org/10.1016/j.ijbiomac.2017.11.054

35. Tong, Q., \& Qiu, F. (2020). Population growth and land development: Investigating the bi-directional interactions. Ecological Economics, 169, 106505. https://doi.org/10.1016/j.ecolecon.2019.106505

36. Verma, D., \& Gope, P.C. (2015). The use of coir/ coconut fibers as reinforcements in composites. In Biofiber Reinforcements in Composite Materials (pp. 285-319). Elsevier. https://doi. org/10.1533/9781782421276.3.285

37. Widnyana, A., Rian, I.G., Surata, I.W., \& Nindhia, T.G.T. (2020). Tensile Properties of coconut Coir single fiber with alkali treatment and reinforcement effect on unsaturated polyester polymer. Materials Today: Proceedings, 22, 300-305. https://doi. org/10.1016/j.matpr.2019.08.155 